http://jmscr.igmpublication.org/home/ ISSN (e)-2347-176x ISSN (p) 2455-0450

crossref DOI: https://dx.doi.org/10.18535/jmscr/v9i3.03

Journal Of Medical Science And Clinical Research

\title{
Symptomatic Improvement and Mucosal Healing in UC Patients - A Short- Term Randomised Trial Comparing Tofacitinib with Mesalamine
}

\author{
Authors \\ Dr Swarup Chakraborty ${ }^{1}$, Dr Pinaki Roy ${ }^{2}$ \\ ${ }^{1}$ Associate Professor, Surgery, Calcutta National Medical College, Kolkata- 14 \\ ${ }^{2}$ Assistant Professor, Surgery, Calcutta National Medical College, Kolkata-14 \\ Corresponding Author \\ Dr Swarup Chakraborty
}

\begin{abstract}
Background: Inflammatory bowel disease (IBD) recently, since the last few decades have found a respectable position amongst the Indian sub-continent owing to the emerging transcendence of stress and westernization of Indian food culture. Usually, it is characterized as Crohn's disease (CD) and Ulcerative colitis (UC). Spontaneous uncontrolled mucosal flare-ups hallmark as its sine- qua non feature. UC was firstly described by Sir Samuel Wilks in 1859, inflammation being restricted to the colon. CD as described and named after Dr. Burrill B. Crohn, usually includes the entire gastrointestinal tract (GIT). Ulcerative colitis (UC), a chronic inflammatory disorder still idiopathic, presents typically with symptoms such as blood mixed diarrhea, pain abdomen and rectal urgency. UC is a complementary, clinical cum colonoscopy diagnosis. Remission induction and maintenance of the remission are its primary goals. For mild-to-moderate disease, oral or rectal formulations of 5-aminosalicylic acid are usually used. In moderate-to-severe flare- ups of UC, corticosteroids are usually used, with or without another class of medications such as thiopurines or biologics including anti-tumor necrosis factor, antiintegrins.

Janus kinase inhibitors (Tofacitinib) is a new class of drug used for remission induction that has been very recently FDA approved in 2018.

Methods: This study is a short-term approach to consider the symptomatic score improvement and colonoscopy healing comparing the time tested Mesalamine with its newer contender Tofacitinib in the form of a randomized controlled trial amongst 100 patients of mild to moderate UC, over a period of 06 months.

Results: Both groups had statistically comparable results, though Tofacitinib showed faster signs of colonoscopy healing but showed up with slightly more side effects when compared with Mesalamine.

Conclusion: The current study is an eye-opener so as to, not quickly jump to newer drugs but consider the correct timing of a newer drug introduction for better long-term remission of a crippling disease like $U C$ that requires life style modifications as an essential criterion in addition to medicines for symptomfree remission and maintenance.
\end{abstract}

\section{Introduction}

The present study is a novel attempt at considering the major two goals of achieving clinical remission and colonoscopy corroboration 
of effective healing, that every treating surgeon wishes to achieve to avoid complicating surgical procedures that increase the morbidity and mortality rates of UC patients presenting at the surgical department. UC is an idiopathic, chronic inflammatory disorder of the colonic mucosa that commonly involves the rectum and may extend in a proximal and continuous fashion to involve other parts of the colon ${ }^{1,2}$ The disease typically affects individuals in the second or third decade of life with hallmark clinical symptoms of blood mixed diarrhea with rectal urgency andtenesmus. $^{3,4}$ Exacerbations and remissions hallmark its clinical spectrum, both of which might occur spontaneously or during the treatment schedule. ${ }^{5,6}$. However, even after medical therapy, nearly $15 \%$ of patients usually require surgery as treatment of UC or for tackling its complications.

Till date, the incidence of inflammatory bowel disease (IBD) is highest in North America and Western Europe. However, incidence of IBD is recorded to be at an increasing trend in continental Asia. ${ }^{7,8}$ owing to life style changes and adopting food habits leading to coupling up of the stress cascade. A study in Punjab (North India) also showed prevalence and incidence rates of 4.43 per million and 0.6 per million respectively ${ }^{10}$. The detailed etio-pathogenesis of the disease is yet to be fully understood. Genetic factors, histoepithelial defects and triggering environmental factors all seem to act in conjunction. Currently, discovery have been noted of multiple genetic and environmental factors that have a pivotal role to play in development of UC. ${ }^{9}$ A westernized lifestyle and diet including reduction of tobacco use, a fried-rich fatty diet, stressful go of life and medication overuse, all of which are companion of high socioeconomic status are all associated with the development of UC. ${ }^{11,12}$

Mesalamine is useful in controlling active inflammation, maintaining remission and for chemoprevention specifically suited for UC. It has the advantage of being generally well- tolerated and safe for long-term use with flexible dosing. Mesalamine, also known as (5- ASA), is the first- line treatment for IBD and remains the gold standard treatment for mild to moderate UC. European Crohn's and Colitis Organization Consensus states that oral 5-ASA is not recommended for the treatment of mild to moderate Crohn's disease. ${ }^{13}$ Clearly, there is conflicting evidence regarding the efficacy of oral amino salicylates in active $\mathrm{CD}$ and their use in mild to moderate $\mathrm{CD}$ is a highly debatable topic. ${ }^{14}$

\section{Mesalamine}

The action of mesalamine is believed to be predominantly topical at the site of inflammation, especially within the colon. The clinical target is to achieve maximal delivery of the active drug 5-ASA - to the colonic mucosa along with reduced systemic absorption.

Therefore clinical picture coupled with corroborative colonoscopy findings suggested by continuous colorectal involvement constitutes the present diagnostic criteria of UC.

\section{Tofacitinib}

Tofacitinib is a Janus kinase inhibitor and was recently licensed in 2018 for treatment of moderate-to-severe variant of active $\mathrm{UC}{ }^{17}$ It is indicated for treatment of adult patients with moderate-to-severe UC, but it is usually recommended to be used as single drug therapy. Patient compliance after thorough explanation of the drug including it's side effects are mandatory criteria of starting the therapy. Available as $5 \mathrm{mg}$ and 10 tablet dosage, it is usually administered twice a day. The lowest effective dose is titrated for maintenance. ${ }^{16}$ weeks is the time mark for response measurement, failing which $10 \mathrm{mg} \mathrm{BD}$ dosage should be discontinued.

Moderate- to-severe renal disease should see a cut down to a half-daily dosage as compared to patients with normal kidney functions. Severe hepatic disease is a contraindication for using the molecule. Similarly patients receiving

CYP 3A4 inhibitors like ketoconazole should have the doses reduced by half. ${ }^{17}$

Tofacitinib have been recorded with some serious and sometimes fatal bacterial, mycobacterial, viral 
and opportunistic fungal infections like anti tumor necrosis factor. ${ }^{17}$ A $5 \mathrm{mg}$ twice daily dosage is much better tolerated than 10mg dosage, including opportunistic herpes zoster infections rates, which have been seen to be more frequently associated with $10 \mathrm{mg}$ twice daily dosage. ${ }^{17}$ It is the recommended consensus for these patients to receive vaccination against zoster prior to start of treatment.

Before starting tofacitinib, all patients should undergo thorough evaluation and tests for latent or active TB and subjected to documented to scrutiny by infectious disease expert, whose clearance is mandatory. In patients who are tested positive for latent $\mathrm{TB}$, it is recommended to consult an infectious disease specialist to whether or not, initiate anti-TB therapy before starting the treatment with tofacitinib. Other side effects like neutropenia should mandate intra- treatment episodicroutine blood tests including differential counts and peripheral blood slide analysis. Increase in liver enzymes of up to three times the upper limit of normal has also been observed necessitating dose reduction of tofacitinib in these patients to revert back to normalcy. ${ }^{18}$

\section{Inclusion Criteria}

1. All cases of mild to moderate UC ( $>=18$ years of age).

2. Only those cases that consented to the study with signing an informed consent letter.

3. All cases who had a normal renal and cardiac profile.

4. All cases received quadrivalent MMRV vaccination in group B (Tofacitinib).

\section{Exclusion Criteria}

1. All severe cases of UC.

2. Those who did not consent to the study.

3. All cases of active or chronic renal disease.

4. Cardiological unstable patients.

5. All patients with altered liver enzymes.

6. All patients on any ketoconazole therapy
7. Cases with active or latent tuberculosis.

\section{Methods}

100 Patients that presented with mild/ moderate, disease - stratification based on clinical severity were randomly divided into 2 equal groups. Group A received Mesalamine 1.2gm twice daily, while Group B received Tofacitinib $05 \mathrm{mg}$ twice daily dosage. The goals of treatment were induction of remission followed by maintenance of remission along with steroid-free treatments for long-term management. $^{15}$

The Truelove and Witts criteria were used to segregate patients as mild, severe, or fulminant colitis (Table 1). 40 Patients categorized as having mild clinical disease were there in both groups and had less than four stools per day with or without blood with no signs of systemic toxicity. Mild crampy abdominal pain with occasional tenesmus were common clinical symptoms. 10 patients of both groups presented with moderatedisease and had abdominal pain, frequent loose blood mixed stools (typically<4-6> motions per day), and mild anemia which however was self limiting and did not require any blood transfusions. Signs of systemic toxicity, such as fever was not recorded. With the Truelove and Witts criteria, the colon was evaluated endoscopically either with a sigmoidoscopy or colonoscopy, depending on the clinical presentation and validated scores of Mayo Endoscopy scoring system was recorded. The endoscopic Mayo score is a classification of UC, based on the erythema, erosions or ulcers, and/or severe mucosal friability into mild, moderate and severe disease. The management of severe and fulminant clinical disease which is entirely different from that of mild-to-moderate disease was excluded from the study. Step-up dose escalation was not required for treating the 10 patients from either groups and no titration of dosage, to TID therapy schedule, escalating from BD schedule was required. All the 10 patients, of either groups who presented with moderate disease responded favorably by the end of 8 
weeks of treatment.

Eligible patients ( $\geq 18$ years of age), with a diagnosis of active UC (total Mayo score of 6-12 and mild to moderate active disease on sigmoidoscopy/ colonoscopy) were randomized to receive oral tofacitinib $05 \mathrm{mg}$, or mesalamine $1.2 \mathrm{gms}$ twice daily (BID) for 8 weeks. PROs were assessed by the Inflammatory Bowel Disease Questionnaire (IBDQ) and the Inflammatory Bowel Disease Mayo score at induction and at the end of 08 weeks.

\section{Discussion and Statistical Analysis}

Both the study groups A and B showed significant response with the Mesalamine group scoring 171.4 (IBDQ Score) as against 174.5 (IBDQ) scored by the Tofacitinib group.
None of the 10 patients of either group presenting with moderate- severe disease required dose escalation. The endoscopic Mayo scoring showed significant improvement in both study groups, at the end of 08 weeks when compared with the initial survey status. Both the groups recorded favorable outcome. Group A (Mesalamine) had favorable outcome of 171.4 in IBDQ score and a significant Mayo score conversion from $+1(80 \%)$ as baseline to $30 \%$ at the end of 08 weeks. Group B (Tofacitinib) recorded 174.5 IDBQ score and a similar baseline Mayo score conversion from +1 (80\%) to $26 \%$ at the end of 08 weeks therapy. The $\mathrm{P}$ value was $>0.05$ and hence insignificant, which means that both the drugs were statistically indifferent with no added advantage.

\section{Results}

Randomised Trial (IBDQ) Score

\begin{tabular}{|l|c|c|}
\hline IBDQ TOTAL SCORE & MESALAMINE 1.2 GM BD N=50 & TOFACITINIB 5MG BD N=50 \\
\hline Baseline $\mathrm{n}$ & 50 & 50 \\
\hline $\mathrm{N}(4$ wks.) & 50 & 50 \\
\hline $\mathrm{N}(8$ wks.) & 50 & 50 \\
\hline $\begin{array}{l}\text { Bowel function 8 wks. SD } \\
\text { Max score 70 }\end{array}$ & 56.40 & 56.50 \\
\hline $\begin{array}{l}\text { Emotional status 8 wks. SD } \\
\text { Max 84 }\end{array}$ & 64.00 & 64.00 \\
\hline $\begin{array}{l}\text { Systemic symptoms 8 wks. SD } \\
\text { Max 35 }\end{array}$ & 26.00 & 28.00 \\
\hline $\begin{array}{l}\text { Social functions 8 wks. SD } \\
\text { Max 35 }\end{array}$ & 25.00 & 26.00 \\
\hline $\begin{array}{l}\text { IBDQ RESPONSE a/ REMISSION b } \\
\text { 8 weeks }\end{array}$ & 171.4 (remission score) & $40(50)=80 \%$ \\
\hline $\begin{array}{l}\text { LOGISTIC REGRESSION ODDS } \\
\text { RATIO }\end{array}$ & $1.26(\mathrm{C} \mathrm{I} \mathrm{-} \mathrm{0.49,3.26)}$ & $174.5($ remission score) \\
\hline
\end{tabular}

Range of IBDQ total score: Maximal domain score: Bowel function=70; Emotional status = 84; Systemic symptoms = 35; Social function $=35$.- Adapted 19

$\mathrm{P}$ value here is $>0.05$ and hence statistically insignificant.

\section{Results}

Mayo Score Conversion

\begin{tabular}{|l|c|c|}
\hline MAYO SCORE & MESALAMINE GROUP & TOFACITINIB GROUP \\
$\mathrm{N}=100$ & $\mathrm{~N}=50$ & $\mathrm{~N}=50$ \\
\hline BASELINE & $+1=40(80 \%)$ & $+1=40(80 \%)$ \\
SCORE $(\%)$ & $+2=10(20 \%)$ & $+2=10(20 \%)$ \\
\hline & $0=35(70 \%)$ & $0=37(74 \%)$ \\
08 WEEKS SCORE & $+1=15(30 \%)$ & $+1=13(26 \%)$ \\
& $+2=0$ & $+2=0$ \\
\hline
\end{tabular}


Reference tables that have been considered as useful aids for the study are listed below .

Table 1: Truelove and Witt's Severity Index

\begin{tabular}{|l|c|c|c|}
\hline & Mild & Moderate & Severe \\
\hline Bowel motions / day & $<04$ & $04-06$ & $\begin{array}{c}\text { 06 or more + systemic } \\
\text { Upset features. }\end{array}$ \\
\hline Blood in stools & $\begin{array}{c}\text { Small amounts / occult } \\
\text { blood }\end{array}$ & $\begin{array}{c}\text { Between mild and } \\
\text { severe }\end{array}$ & Visible blood \\
\hline Pyrexia recordable & No & No & Yes \\
\hline Pulse $>90$ BPM & No & No & Yes \\
\hline Anemia ESR & No & $\begin{array}{c}\text { No } \\
30 \text { or less }\end{array}$ & 30 \\
\hline
\end{tabular}

Adapted from Sturm et al. 16

Table 2: Endoscopic Mayo Score

\begin{tabular}{|l|c|c|}
\hline $\begin{array}{l}\text { Mucosal appearance at } \\
\text { endoscopy }\end{array}$ & Normal or inactive disease & 0 \\
\hline & $\begin{array}{c}\text { Mild disease } \\
\text { (erythema, decreased vascular } \\
\text { pattern, mild friability) }\end{array}$ & +1 \\
\hline & $\begin{array}{c}\text { Moderate disease (Marked erythema, } \\
\text { absent vascular pattern, friability, } \\
\text { erosions) }\end{array}$ & +2 \\
\hline & $\begin{array}{c}\text { Severe disease (spontaneous } \\
\text { bleeding, ulcerations) }\end{array}$ & +3 \\
\hline
\end{tabular}

Table 3: UCEIS (Ulcerative Colitis Endoscopic Index of Severity) descriptors and definitions

Likert scale (anchor

points)

\begin{tabular}{|c|c|c|}
\hline Descriptor & & Definition \\
\hline & Normal (0) & $\begin{array}{l}\text { Normal vascular pattern.Capillaries clearly defined/with } \\
\text { blurring / patchy loss. }\end{array}$ \\
\hline & $\begin{array}{l}\text { Patchy obliteratio } \\
\text { (1) }\end{array}$ & nPatchy obliteration of vessels. \\
\hline & Obliteration (2) & Complete obliteration \\
\hline Bleeding & None (0) & Visibly nobleed \\
\hline & Mucosal(1) & spots or streaks of coagulated blood which can be washed away \\
\hline & Luminal mild (2) & Little free liquid blood in the bowellumen \\
\hline & $\begin{array}{l}\text { Luminal moderato } \\
\text { severe }(3)\end{array}$ & rFrank bleeds noted \\
\hline Erosions & dNone (0) & Normal mucosa with no visible erosions orulcers \\
\hline ulcers & Erosions(1) & Tiny $(\leq 5 \mathrm{~mm})$ defects in the mucosa, yellowish white \\
\hline & Superficial ulcer (2) & $\begin{array}{l}\text { Larger }(>5 \text { mm)mucosal defects. Discrete fibrin-covered } \\
\text { ulcersbut which remain superficial }\end{array}$ \\
\hline & Deep ulcer(3) & Deeply excavated mucosal defects with slightly raised edges. \\
\hline
\end{tabular}

Adapted from Sturm et al.16

\section{Conclusion}

The present study has its limitations regarding short time interval and a relatively small size. But as an Indian sub-continent study, the sample size is adequate to comment on the lack of relative advantage of the newer drug tofacitinib over the time-tested mesalamine when symptomatic scores and colonoscopy findings are taken as practical yardsticks of clinical well-being and remission maintenance in mild to moderate Ulcerative colitis 
patients.

However, each drug needs fair length phase III trials, before it can be accepted or discarded. This study is an eye-opener to cautiously select and induct any drug to deliver the best benefits of drug to the treated patient.

\section{References}

1. Baumgart DC. What's new in inflammatory bowel disease in 2008? World J Gastroenterol. 2008;14(3):329330. doi: 10.3748/wjg.14.329. [PMC free article] [PubMed] [Cross Ref] [Google Scholar]

2. Ordas I, Eckmann L, Talamini M, Baumgart DC, Sandborn WJ. Ulcerative colitis. Lancet. 2012;380(9853):16061619. doi: 10.1016/s0140-6736(12)601500. [PubMed] [Cross Ref] [Google Scholar]

3. Danese S, Fiocchi C. Ulcerative colitis. N Engl J Med. 2011;365(18):1713-1725. doi: 10.1056/NEJMra1 102942. [PubMed] [Cross Ref] [Google Scholar]

4. Meyers S, Janowitz HD. The "natural history" of ulcerative colitis: an analysis of the placebo response. J Clin Gastroenterol. 1989;11(1):33-37. [PubMed] [Google Scholar]

5. Kornbluth AA, Salomon P, Sacks HS, Mitty R, Janowitz HD. Meta-analysis of the effectiveness of current drug therapy of ulcerative colitis. J Clin Gastroenterol. 1993;16(3):215-218. [PubMed] [Google Scholar]

6. Kornbluth A, Sachar DB. Ulcerative colitis practice guidelines in adults: American College of Gastroenterology, Practice Parameters Committee. Am J Gastroenterol.2010;105(3):501-523. doi: 10.1038/ajg.2009.727. quiz 524. [PubMed] [CrossRef] [Google Scholar] Loftus EV., Jr Clinical epidemiology of inflammatory bowel disease: incidence, prevalence, and environmental influences. Gastroenterology.
1517. doi: 10.1053/j.gastro.2004.01.063. [PubMed] [Cross Ref] [Google Scholar]

7. Ananthakrishnan AN. Epidemiology and risk factors for IBD. Nat Rev Gastroenterol Hepatol. 2015;12(4):205217. doi: 10.1038/nrgastro.2015.34. [PubMed] [Cross Ref] [Google Scholar]

8. $\mathrm{Ng} \mathrm{SC}$, Bernstein CN, Vatn $\mathrm{MH}$, et al. Geographical variability and environmental risk factors in inflammatory bowel disease. Gut. 2013;62(4):630-649. doi: $\quad$ 10.1136/gutjnl-2012- 303661. [PubMed] [Cross Ref] [Google Scholar]

9. A. Sood, V. Midha, N. Sood, A.S. Bhatia, G.Avasthi Incidence and prevalence of ulcerative colitis in Punjab, North India Gut, 52 (2003), pp. 1587-1590

10. Danese S, Sans M, Fiocchi C. Inflammatory bowel disease: the role of environmental factors. Autoimmun Rev. 2004;3(5):394-400. doi: 10.1016/j.autrev.2004.03.002. [PubMed] [Cross Ref] [Google Scholar]

11. Birrenbach $\mathrm{T}$, Bocker U. Inflammatory bowel disease and smoking: a review of epidemiology, pathophysiology, and therapeutic implications. Inflamm Bowel Dis. 2004;10(6):848-859. [PubMed] [Google Scholar]

12. Travis SP, Stange EF, Lemann M, et al. European evidence-based consensus on the diagnosis and management of Crohn's disease: Current manangement. Gut. 2006;55(Suppl 1):16-35. [PMC free article] [PubMed] [Google Scholar]

13. Hanauer SB, Sandborn W. Management of Crohn's disease in adults. Am J Gastroenterol. 2001;96:635-43. [PubMed] [Google Scholar] Kornbluth A, Sachar DB. Ulcerative colitis practice guidelines in adults: American College of Gastroenterology, Practice Parameters Committee. Am J Gastroenterol. 2010;105 (3):501-523. doi: 10.1038/ajg.2009.727. quiz 524. [PubMed] [Cross Ref] [Google 
Scholar]

14. Kornbluth A, Sachar DB. Ulcerative colitis practice guidelines in adults: American College of Gastroenterology, Practice Parameters Committee. Am J Gastroenterol.2010;105(3):501-523. doi: 10.1038/ajg.2009.727. quiz 524. [PubMed] [CrossRef] [Google Scholar]

15. Sturm A, Maaser C, Calabrese E, et al. ECCO-ESGAR guideline for diagnostic assessment in ibd part 2: Ibd scores and general principles and technical aspects. J Crohns Colitis. 2018;13(3):273-284. doi: 10.1093/ecco-jcc/jjy114. [PubMed] [Cross Ref] [Google Scholar]

16. Sandborn WJ, Su C, Sands BE, et al. Tofacitinib as induction and maintenance therapy for ulcerative colitis. $\mathrm{N}$ Engl $\mathrm{J}$ Med. 2017;376(18):1723-1736. doi: 10.1056/NEJMoa1606910. [PubMed] [Cross Ref] [Google Scholar]

17. Olivera P, Danese S, Peyrin-Biroulet L. JAK inhibition in inflammatory bowel disease. Expert Rev Clin Immunol. 2017; 13(7):693-703. doi: 10.1080/1744666X.2017.1291342.

[PubMed] [Cross Ref] [Google Scholar]

18. Randomized trial of tofacitinib in active ulcerative colitis: analysis of efficacy based on patient-reported outcomes Julián Panés, Chinyu Su, Andrew G Bushmakin, Joseph C Cappelleri, Carla Mamolo\& Paul Healey BMC Gastroenterology volume 15, Article number: 14 (2015). 